\title{
Benefits and Employment: How Problem Drug Users Experience Welfare and Routes into Work
}

\author{
LINDA BAULD*, JENNIFER MCKELL**, COLIN CARROLL***, \\ GORDON HAY*** and KATHERINE SMITH ${ }^{* * * *}$
}

\author{
* University of Stirling, Stirling FK9 4LA \\ email: linda.bauld@stir.ac.uk \\ ** University of Stirling, Stirling FK9 4LA \\ email: j.e.mckell@stir.ac.uk \\ *** University of Glasgow, Glasgow, G12 8QQ \\ email: colin.carroll@glasgow.ac.uk,dr.gordon.hay@gmail.com \\ **** University of Edinburgh, Edinburgh, EH8 9LD \\ email: Katherine.Smith@ed.ac.uk
}

\begin{abstract}
Increasing the conditionality of welfare benefits is a growing trend in many developed countries, particularly in relation to some groups who may be perceived as undeserving of state support. Problem drug users (PDUs) are one such group, and in the UK most PDUs do not work and a high proportion claim benefits. Facilitating the movement of these individuals into employment is a policy aim, because it is believed to improve the circumstances of drug users (and promote future abstinence) and because moving all groups off benefits and into work is a primary purpose of recent welfare reforms. Yet little is known about the interactions of PDUs with the UK benefits system or how recent moves to increase the conditionality of benefits are likely to affect this vulnerable group. This paper begins to address this gap by exploring the perceptions that PDUs and relevant frontline staff have of drug users' interactions with the welfare system and the factors affecting their prospects for employment. The findings suggest some aspects of recent welfare reforms, notably the simplification of benefits, may help PDUs interact with the system. However, the data also reinforce claims that the increased use of sanctions is unlikely to succeed in improving employment rates amongst this group without intensive support and demand-side interventions.
\end{abstract}

\section{Introduction}

Illicit drug use is an established problem in a number of countries, and the global burden of disease and disability due to this drug use has continued to rise in recent years (UNODC, 2012). The use of illicit drugs is a significant cause of premature mortality amongst young adults in most developed countries (UNDCP, 2000; Degenhart et al., 2003; Bargagli et al., 2006). In the UK, for example, one in twenty adults admitted to using illicit drugs in the past month (Hoare and Flatley, 2008; MacLeod and Hickman, 2010). Although the most commonly used drug is cannabis, there is particular concern in the UK and other countries about 
the use of 'problem' drugs, typically heroin and crack cocaine. For the individual, drug misuse ${ }^{1}$ can lead to physical and mental health problems, unemployment, imprisonment, homelessness, poverty, debt and the loss of social support. For communities and society, drug misuse impacts upon the delivery of health and social care services and levels of crime. In light of these issues, a great deal of effort has been put into trying to accurately estimate the numbers of problem drug users (PDUs - i.e. users of opiates, mainly heroin, or crack cocaine) in different parts of the UK (e.g. Hay et al., 2008; Gordon et al., 2006; Singleton et al., 2006). In 2006/2007, it was estimated that there were almost 330,000 PDUs in England (Hay et al., 2008).

One of the key challenges posed by problem drug misuse is unemployment. A study investigating the effectiveness of drug treatment in England, using a representative sample of drug users entering treatment, found that only 9 per cent of participants were employed, with a further 2 per cent in education or training (Jones et al., 2007). Due to the high risk of unemployment amongst this group, most PDUs are also likely to receive welfare benefits. A study into the extent of benefit uptake in England, estimated that there were 267,00o PDUs claiming benefits in 2006 (Hay and Bauld, 2008). This indicates that, while PDUs made up only 1 per cent of the working-age population, they account for more than 6 per cent of those claiming the Department for Work and Pension's (DWP) 'main' benefits.

Not only is unemployment connected to other difficulties associated with problem drug use, such as poverty and debt, but it is itself a risk factor for mental health problems and premature mortality (Dorling, 2009). It is not surprising, therefore, that employment has been increasingly recognised by the UK government as an important component of the recovery process for PDUs (HM Government, 2008; Singleton and Lynam, 2009). However, previous research has shown that many drug users encounter multiple barriers to employment, including poor levels of education and skills, problems engaging with support staff and employers, limited provision of support services and the stigma associated with being a drug user (Sutton et al., 2004). Drawing on qualitative research with PDUs and professionals, this paper explores some of the complexities involved in the interlinked policy areas of drug misuse, welfare reform and unemployment. These findings are contextualised by a brief review of recent welfare reforms in the UK, placed in an international context. The conclusion reflects on how proposed changes are likely to impact on PDUs.

\section{The increasing trend towards the conditionality of welfare benefits in the UK and elsewhere}

In the UK, as in other countries, welfare benefits for the unemployed have, in principle, always been conditional upon claimants' availability for employment (Harris, 2008). However, over the past two decades, the conditionality attached 
to this requirement has increased, in terms of the extent to which claimants are required to demonstrate their willingness to work and in terms of the sanctions imposed on those who do not comply (Harris, 2008). This reflects a broader trend towards activation and conditionality in welfare reforms in developed countries (McDonald and Marston, 2005), with recent welfare reforms in New Zealand bearing a particularly strong resemblance to those of the UK (Lunt et al., 2008). A similar trend is also evident in Australia, Denmark, Germany, the Netherlands and the USA, with various degrees of policy 'transfer' occurring across these contexts (Daguerre, 2007; Dwyer and Ellison, 2009).

In the UK, the 1989 Social Security Act marked a return to an earlier notion that the law should require claimants not only to indicate availability for work but also to demonstrate what steps they were taking to obtain 'employed earner's employment' (Harris, 2008). Then, in 1996, unemployment benefit and income support were replaced with the Jobseekers' Allowance (JSA), a benefit that signifies a clearer shift towards a more 'activational welfare model' (Harris, 2008). JSA claimants are required to provide more evidence of their efforts to obtain work and harsher penalties were introduced for those who did not comply.

After Labour were elected in 1997, Jobseekers' Allowance remained in place, although a series of 'New Deal' schemes, which also aimed to facilitate routes into employment, were also implemented (Harris, 2008). However from 2008, the UK Labour government introduced significant welfare reforms (DWP, 2008). These reforms expanded conditionality in the UK benefit system, placing a new emphasis on ability (rather than inability) to work by introducing Employment and Support Allowance (ESA) for new claimants of Incapacity Benefit, with 'work capability' assessments for applicants. These reforms extended conditionality requirements to PDUs who, in return for benefit payments, were expected to 'agree a rehabilitation plan, and to make real efforts to make progress against it' (DWP, 2008: 118). As with other benefit claimants, the government stated that failure to meet these requirements would result in sanctions, including a temporary reduction in benefit payments (DWP, 2008), although it was unclear precisely how this would work in practice (see Harris, 2010). By 2009, official statistics were already indicating that far more new claimants were being classified as 'fit for work' under the new assessment system (Harris, 2010).

The Conservative-Liberal Democrat coalition government, elected in 2010, announced further reforms to the UK welfare system in a White Paper entitled Universal Credit: Welfare that Works (DWP, 2010). In addition to proposals aimed at simplifying the system by replacing some benefits (Working Tax Credit, Child Tax Credit, Housing Benefit, Income Support, Jobseeker's Allowance and ESA) with a single benefit called Universal Credit, the White Paper extends the principle of conditionality yet further. As the reforms are implemented, welfare office ('Jobcentre Plus') advisors will be able to require jobseekers to: attend their local office more frequently, demonstrate that they have taken steps towards returning 
to work, broaden their job search earlier in their claim; undertake activity to address a skills need and, in some cases, undertake Mandatory Work Activity. The latter will involve a work placement of up to four weeks, not necessarily related to the kind of employment the benefit recipient is seeking but with the intention of getting them back into the routine of working. For those who do not meet these requirements, significant sanctions will follow: failure to prepare for work will lead to all benefits payments ceasing until compliance is achieved, and for a fixed period after compliance; failure to provide evidence of active employment-seeking and being work-ready will lead to payment ceasing for up to three months; failures that are considered particularly serious, such as not accepting a reasonable job offer or attending Mandatory Work Activity, will result in the ceasing of benefit payments for a period of at least three months. These conditions will not apply to people considered 'unable to work' and the White Paper states that the system will 'maintain safeguards for vulnerable people and ensure that mental health and substance abuse problems are taken into consideration' (DWP, 2010: 29). However, only people with a serious disability or health condition, carers, lone parents or lead carers with a child under the age of one will not be subject to conditionality.

The 2010 White Paper provides no guidance on how people with substance abuse issues, including PDUs, will be categorised. PDUs, clinicians and researchers have argued that drug dependence is an illness (Cebulla et al., 2004; McLellan et al., 2000). Despite this, recent UK policies have often focused on the criminal, rather than the health, aspects of drug use (Duke, 2006). It is therefore unclear whether the new welfare system will categorise PDUs as being unable to work for health reasons or require them to meet new conditionality requirements.

While recent policies appear to have succeeded in helping some people back into employment in the UK (Gregg, 2008), there is far less evidence that they have been successful in helping people in difficult circumstances, such as those living in areas of low employment (Joyce et al., 2010) or those with multiple problems and complex needs (Dean, 2003; Millar, 2000). There is very little direct evidence of the impact of welfare benefit conditionality on PDUs in the UK (Singleton and Lynam, 2009). The previous Labour administration evaluated programmes in this area, but the findings are mixed and, again, highlight that it is extremely difficult to facilitate employment for individuals with complex or multiple needs (Hales et al., 2009; Barnes et al., 2010). Evidence from the USA also suggests increased conditionality can have variable results for PDUs. For example, one US study found evidence that substance abuse treatment was effective in increasing employment rates but also noted that government mandated drug testing may drive drug-using employees to 'abandon the search for legitimate work activities' (Montoya and Atkinson, 2002: 140). Other US studies indicate that screening for drugs and alcohol may not reduce welfare participation (Cheng and Lo, 2010), 
that increased conditionality may not reduce drug use (see Harris, 2010) and that it may impact negatively on drug users' families (e.g. Allard, 2002; Montoya and Atkinson, 2002). A UK-based review of the limited available evidence concluded that these reforms carry a risk of similar unintended consequences (UKDPC, 2008).

One of the criticisms of recent efforts to move people off benefits and into work is that interventions tend to focus on supply-side initiatives and have failed to adequately address demand for jobs (Dean, 2003; Joyce et al., 2010). Singleton and Lynam (2009) argue that this is a particularly important omission for PDUs, noting that a survey of employers found two-thirds (ninety out of 135) 'would refuse to employ a former heroin or crack-cocaine user, even if they were otherwise suitable for the job' (Spencer et al., 2008, cited in Singleton and Lynam, 2009). Surveys have also found employers are often extremely reluctant to employ people on methadone (Scott and Sillars, 2003; Spencer et al., 2008; Singleton and Lynam, 2009).

In this article, we aim to explore the possible impact of welfare reforms, placing greater conditionality on PDUs. Using data taken from interviews with PDUs and professionals in the UK, we examine views relating to PDUs' experiences of claiming benefits, finding employment and welfare reform (including conditionality). To further set these findings in context, we also include, where appropriate, some comparisons with data from interviews with problem alcohol users and related professionals, collected as part of a subsequent study (Bauld et al., 2010).

Given the paucity of research exploring this issue, this paper should be of significant interest to academics and policymakers in the UK as well as in other countries with a similar approach to welfare benefits, where concern about drug dependency issues also exists. As noted above, the increasing trend towards activation and conditionality is evident in Australia, Canada, Denmark, the Netherlands, New Zealand and the USA, all of which also have concerns with substance abuse (Degenhardt et al., 2009).

\section{Methods}

The results presented originate from a study commissioned by the DWP that considered the extent and nature of benefit uptake amongst PDUs in England. This study used qualitative methods and involved interviews with 75 PDUs and ten associated professionals in five drug action team areas across England. These five areas were selected to ensure coverage of both urban and semi-rural settings, as well as communities where drug misuse was identified as a problem. Adults with current or previous substance misuse problems were recruited to the study via contact with drug action team staff. Interviews took place in February and March 2009. 
Interviewees were predominantly male, and aged between twenty-two and sixty-five years, with most in their thirties or forties. The age and gender profile of interviewees was broadly similar to that of the PDU population in the UK as a whole (Hay and Bauld, 2008). With some notable exceptions, most participants had left school with no qualifications, though a number had gone on to attend further education or training and had achieved vocational qualifications. Many participants had received treatment for their drug misuse on more than one occasion.

The ten professionals interviewed as part of this study were recruited on the recommendation of staff in drug action teams assisting with the research. Many worked in the voluntary sector and some were employed by major organisations in the drug treatment and support field. All interviewees were employed in a role that involved regular, in most cases daily, contact with adults with substance misuse problems, in particular PDUs, and some interviewees had knowledge and experience of the benefit system.

\section{Findings}

This section details the findings from the study relating to PDUs' experiences of the benefit system and Jobcentre Plus, and routes into employment.

\section{The benefit system and Jobcentre Plus}

In interviews, PDUs talked about their experiences of claiming and receiving benefits: the application process, attending appointments, Work Capability Assessments and appeals and contact with Jobcentre Plus staff. The professional interviewees explored their perceptions of how PDUs accessed benefits and the relationship between the benefit system and their own role, or that of their agency.

\section{Current benefit receipt}

All PDUs interviewed were either currently receiving benefits, or had received benefits in the past, with the majority of those in receipt of benefits receiving out-of-work benefits. The most common were Income Support (IS), Incapacity Benefit (IB) and Jobseeker's Allowance (JSA) but some interviewees reported claiming the new Employment and Support Allowance (ESA). Other benefits received included Disability Living Allowance (DLA), Carer's Allowance, Child Benefit, Working Tax Credit, Housing Benefit, the State Pension and Statutory Sick Pay. Claims for sickness benefits were largely due to mental health problems such as anxiety and depression, and in some cases schizophrenia and posttraumatic stress disorder. Some respondents directly attributed their claims to ongoing recovery from drug use.

Income Support and Incapacity Benefit were the benefits most commonly identified by professionals as being accessed by PDUs, although some clients 
received Jobseeker's Allowance and made attempts to comply with the requirements of that benefit (for example, attending work-focused interviews) while accessing treatment. Problem alcohol users interviewed as part of a later study also claimed a range of benefits, though were less likely to be receiving IS or JSA (Bauld et al., 2010). As with the PDUs interviewed, the problem alcohol users were also claiming due to mental health issues such as depression; however, physical health problems were more of a feature for alcohol than drug users.

\section{Claiming benefits}

Interviews with both PDUs and professionals highlighted a number of difficulties in the process of claiming, relating to: procedural requirements, PDUs' relationships with benefit officials, the sensitivity of processes to the needs of PDUs' and the ability of individuals to cope with the benefit system.

Although most PDUs interviewed had a good knowledge of the benefit system, some participants had less, which was complicated by the poor availability of advice services in certain research areas. A few interviewees mentioned difficulties filling in benefit application forms and requiring extra help. The application form for Disability Living Allowance was singled out as being particularly difficult to complete:

The forms are extremely lengthy and really specific. Like, they talk about hours in a day, and with what I've got wrong with me, it becomes very stressful ... and they refused, to begin with, and I had to appeal and then they agreed. So it was a very difficult process, probably why I'd taken so long to actually claim. I know that I tried filling out a form a few years ago and it was too much but when I was given housing I had this key worker to sit me down and do it with me.

A small number of respondents reported problems with attending appointments in relation to their claims, due to transport issues or when appointments clashed with treatment requirements. Many respondents felt uncomfortable with the environment in which Jobcentre Plus staff conducted interviews and a particular concern was the use of telephone help-lines instead of face-to-face meetings. Several respondents felt they had little opportunity to speak to a member of staff. The relationship between benefit claimants and Jobcentre Plus staff was believed to be further strained due to the perceived stigma associated with drug use, with several respondents feeling that benefit officials had a negative attitude towards them, either because of their ongoing benefit claims or their drug use.

PDUs reported that they had disagreements with Jobcentre Plus over their ability to work, which is important in light of the moves towards greater conditionality. Respondents who had been receiving benefits due to health reasons talked of feeling pressured into moving on to Jobseeker's Allowance 
to prepare for employment, although they did not feel ready to work due to ongoing addiction. This was true even amongst participants who were keen to return to work in the near future:

I was on the sick for a bit and they told me that they wanted me to come off the sick. I was saying to them, 'well, I'm still in the same position I was in a year or so ago, I'm still depressed, I'm still on drugs, I've still got care taken of me' and so they suspended my sick money.

When I lost my children I went on Jobseeker's for about three years, four years and then I went on Incapacity Benefit for about two years, then they decided that I was fit enough to go back to work. I was rather annoyed because even though I'm desperate to go back to work I still feel that I am not fit because I'm having to rely on the subutex (substitute medication).

Interviewees also said their experience of the 'Work Capability' medical assessments suggested this process was not appropriate to their individual needs. For example, one woman felt that the examination process appeared to have been designed with a focus on physical mobility difficulties, and without sufficient consideration given to mental health issues.

They've sent me my medical and you know, it's a point system. Well, it was all geared to people with limited mobility. And it was very difficult to answer the questions that they wanted you to answer, around mental health problems, especially addiction.

Two respondents described the impact of such processes on their ability to cope and maintain their recovery. Participants said that complying with the requirements of the benefit system had been stressful, particularly in the transition from one benefit to another, with a key concern being the ability to continue paying their bills.

Some comparisons can be drawn between problem drinkers and PDUs in their experience of these aspects of the benefit system, drawing on a subsequent study. Alcohol users were overall more positive about their interactions with Jobcentre Plus staff than PDUs, but were equally critical of the medical assessments required to establish eligibility for some benefits. The majority of problem alcohol users interviewed commented that they found the process insensitive to their needs. In turn, some alcohol users felt they had been pushed to return to work before they were ready (Bauld et al., 2010). This suggests that those whose inability to work is caused at least in part by addiction may feel more stigmatised and treated with less understanding within the welfare system than, for example, those with physical disabilities not caused by alcohol or drug misuse.

Professionals commonly highlighted procedural barriers to accessing benefits, similar to those mentioned by clients, including form-filling and attending appointments. They discussed the effort and persistence required to initiate a claim, the intricacies of the appeal process following a failed medical assessment (noting that during an appeal PDUs can find themselves without an 
income) and issues of language, literacy and entitlement (particularly for non-EU nationals with drug problems). In addition, they highlighted how the sometimes chaotic lifestyle of PDUs often involved problems with housing and therefore capacity to receive and respond to correspondence, making claiming difficult.

Professionals talked in detail about how the behaviour of their clients could make accessing benefits difficult.

They can become quite angry and frustrated, so it's not productive. They lose their temper and then they're asked to leave. Others are still on drugs, high medication, if they're on say, about $125 \mathrm{mg}$ of methadone, or they're still using drugs, you can't expect a drug user to be able to understand any system because they're just not with it.

Professionals also pointed out that some of the drug users they had seen survived outside the benefit system; they either did not bother to try to qualify because the income needed for drug use exceeded benefit levels ${ }^{2}$ or did not feel they qualified.

In their own heads they don't think they qualify. They obviously can qualify, but getting the motivation to get down there, face somebody and be constructive in what they're trying to they can't do it. Because most of them have been out for a long time. Long-term users, they can't be bothered with all that process. They just go out and rob something, shoplift it, that's the way it works.

Although the interviews took place before the UK's current ConservativeLiberal Democrat coalition government was elected, there was some knowledge amongst professionals of proposals for welfare reform. They understood that there would be tighter conditions of entitlement, including the requirement for PDUs to access treatment. Professionals had mixed views about these changes: some were sceptical about increased conditionality and felt that it would deter drug users from claiming and therefore from recovery. However, some welcomed the changes including the intention to discourage reliance on social security and reward recovery and engagement with training and employment opportunities.

Professionals also discussed facilitators to accessing benefits, most notably the role of support or advocacy in negotiating the system. A number of their roles involved advocacy for adults with drug misuse problems: assisting with benefit claims, providing support with housing and family issues, attending appointments (including in the criminal justice system) and arranging training or volunteer work. Perhaps not surprisingly, these interviewees saw the advocacy element of their role as important.

Professionals working with problem alcohol users in a subsequent study highlighted that their clients had similar difficulties to those experienced by PDUs (Bauld et al., 2010). Clients in treatment for alcohol misuse lacked necessary understanding of the benefit system, and many experienced difficulties 
in complying with benefit rules and procedures, particularly 'work capability' assessments.

\section{Routes into employment}

Interviewees discussed barriers and facilitators to employment for PDUs. Only a small proportion of the seventy-five PDU interviewees were in full- or part-time legal employment at the time of the study and professionals emphasised that the vast majority of the drug users they encountered (who were primarily engaged in treatment) were unemployed.

\section{Barriers to employment}

A common theme was the issue of poor self-confidence, in many cases reflecting mental health problems such as depression and anxiety. Respondents discussed feeling incapable of meeting demands in relation to work and jobhunting, as well as in relation to other aspects of their everyday lives. Other interviewees described the barrier of physical health problems: two discussed having Hepatitis $\mathrm{C}$, contracted as a result of injecting drugs, whilst two others discussed ongoing work-related injuries.

Respondents felt their employment prospects were restricted by having had a poor education and therefore few skills and qualifications. Some interviewees reported feeling daunted by the prospect of producing a $\mathrm{CV}$ and attending interviews; others discussed the issue of trying to account for long gaps in their $\mathrm{CV}$ and a lack of references.

Respondents also outlined the damaging stereotypical perceptions of drug users that they had encountered, and described how it was very difficult to gain and sustain the trust of an employer. Similarly, respondents were mindful of employers' likely negativity towards a criminal record, or previous incarceration.

Interviewees also highlighted the difficulty of holding down a job while continuing to receive treatment. They were unsure how employers would feel about employees attending treatment sessions, or collecting substitute prescriptions, during working hours. Some worried that medication would have an impact upon their ability to work.

The side-effects of all my medication and the health problems that I do have, I find that they inhibit me, and if I was to go back to work, I'd have to find a very sympathetic employer.

Perhaps unsurprisingly, ongoing drug use while in employment was also seen as a barrier to sustaining a job. Interviewees described how they had previously worked or were working while also using (even if they were also taking medication) and how difficult it is to maintain a job whilst struggling with an addiction. For example, drug use can increase the risk of injury in manual work, and undermine the ability to function in social situations. 
Professionals were acutely aware of the barriers to employment faced by PDUs and raised many of the same issues, including mental health problems and meeting treatment and medication requirements. They also recognised that many drug users had spent little time in the work force, either having never worked or having only limited work experience. In some cases, this situation was seen as the result of drug users growing up in communities where unemployment is the norm.

I've worked with some clients who've never worked. Never. I mean, it's just amazing. You can't even think about it, but there are people in poorer sections of [the area] who have never worked. Their fathers and mothers never worked. They were on benefits.

Professionals working with drug users felt that employers' attitudes needed to change, partly through improved public education and understanding of drug use, and that government programmes and financial or other types of incentives to employers to take on adults leaving treatment would make a difference.

\section{Facilitators to employment}

Discussions with PDUs around facilitators to employment included accounts of their experiences of using Jobcentre Plus and the importance of voluntary work. Professionals also viewed voluntary work positively, in addition to advocacy, access to training and opportunities provided by supportive employers.

Some PDUs felt that Jobcentre Plus staff had a poor understanding of their circumstances and the difficulties they faced getting (back) into employment, for example the use of substitute prescriptions and the extent of their impact on drug users' lives.

you could look for work, but they just don't understand. They kept on saying to me 'don't declare you're on medication' and I kept on saying to them, 'what happens if I'm liable for it, though', know what I mean? And they still didn't understand.

Several interviewees felt that Jobcentre Plus could do more to address the particular difficulties they face in looking for employment, including: having staff work more closely with them, encouraging applications, following up progress and the provision of flexible and consistent support. There was also a suggestion that Jobcentre Plus should work alongside drug/alcohol support agencies to help people get back into work gradually.

Many of the PDUs not in employment at the time of interview were engaged in voluntary work, which was viewed very positively. While some perceived it to be a good stepping stone into employment, others saw it as being beneficial to recovery generally, due to its ability to improve levels of confidence and occupy spare time. One woman said that in her experience, voluntary work provided greater employment opportunities for recovering drug users than Jobcentre Plus. 
Volunteer work was also seen by professionals as a natural next step from training to employment, and was available for PDUs in most areas.

Professionals felt that PDUs who have been out of the labour market for some time, or who have never worked, need access to training opportunities before even contemplating employment. Along with voluntary work, training and funding for training were repeatedly mentioned as an important part of the pathway to work, and as a first step back into employment. Some also discussed the need to acquire basic or generic skills.

Although examples of supportive employers were provided (local agencies who employed adults post-treatment, and had appropriate policies and procedures in place, including support from treatment agencies and advocates), these were described as few and far between in each case study area, and in all cases the examples given included drug and alcohol agencies. However interviewees expressed some optimism that current efforts to improve the links between treatment agencies and employers would improve attitudes to the employment of PDUs. Some professionals noted that welfare reform had led to changes in the way drug and alcohol agencies were expected to engage with Jobcentre Plus and employment and training providers, for example through the placement of staff with expertise in drug and alcohol services into Jobcentres, and increased partnership working, and this move appeared to be largely welcomed.

While most PDUs interviewed appeared cautious about the prospect of finding employment, most of the problem alcohol users participating in a later study were more confident than PDUs about their ability to return to work, albeit after addressing a number of issues in their lives, particularly achieving abstinence or significantly reducing their alcohol consumption (Bauld et al., 2010). Professionals working with alcohol users were also generally more positive about their future employment prospects. However, as with PDUs, they highlighted the importance of voluntary work and training to help recovering drug users to return to work as well as having their own intrinsic value in terms of building confidence and developing routines.

\section{Discussion}

In the UK, it is not yet clear how PDUs will fit within the benefit system as current proposals for welfare reform are implemented. However, it is likely that there will be a continued expectation that drug users, like most other claimants, should progress towards a point where they can move off benefits and into employment. This approach is not unique to the UK and mirrors developments in other countries, notably Australia and the USA (see Harris, 2010). In one sense, such reforms can be seen as representing a positive approach to PDUs as it signals a commitment to helping these individuals develop healthier, more independent lives. However, despite the value of this aspiration, data presented 
in this paper support the findings of previous studies (Dean, 2003; Singleton and Lynam, 2009) that PDUs face particular difficulties in both interacting with the welfare system and moving into employment. This means that a welfare regime with increased sanctions and no additional support for PDUs, or complimentary interventions to encourage employers to consider providing jobs to this group, may be counterproductive (Allard, 2002; Montoya and Atkinson, 2002; Singleton and Lynam, 2009; UKDPC, 2008).

There was a widespread belief amongst interviewees in this study that some PDUs who were not working did not claim benefits because they viewed the process as too complex or, in some cases, did not believe they were entitled. Further research is required to explore this issue, given that a recent study estimated that 267,000 PDUs claimed benefits in England in 2006 (Hay and Bauld, 2008), which represents just over 80 per cent of the total estimated number of PDUs in England at that time (Hay et al., 2008). This may suggests that the interviewees in our study over-estimated the extent to which non-claiming of benefits amongst this group is a problem or that the estimates of uptake using official figures are too high.

Whatever the reality, our findings suggest PDUs find the welfare system difficult to negotiate and some benefits are perceived to be particularly complex to apply for. In this respect, the proposals outlined in the latest UK White Paper on benefits reform (DWP, 2010) that aim to replace a multitude of different benefits with a universal benefit, coordinated through one government department, may make the system easier for PDUs to access.

However, the difficulties PDUs reported experiencing in obtaining benefits extended beyond problems applying for them. Rather, it was clear that this group of claimants required additional help but that the benefit system was not structured to respond to these demands. For example, PDU interviewees said they would feel most comfortable going into a Jobcentre Plus and being able to talk to someone face-to-face, but reported that they were usually directed to a telephone helpline instead. This supports Dean's sense that, 'though Jobcentre Plus may be able to deliver an effective work-first approach for those who are easy to help, it will struggle to deliver the more flexible and intensive human capital approach that is required for those who are hardest to help [those who] require the kind of intensive casework support and co-ordinated specialist help that lies beyond the capacity of welfare-to-work initiatives' (Dean, 2003: 442). It is possible, as Henderson and colleagues (2006) found, that these latest welfare reforms will mean officials are expected to provide more intensive, personalised attention to clients, entailing more time. Whether relevant staff will be granted the additional resources to enable them to provide this additional support is, however, far from clear.

Our findings also highlight a number of other tensions in the relationships between PDU benefit claimants and welfare officials. For example, interviewees 
reported feeling that officials tended not to understand the practical requirements of drug treatment. For example, some reported experiencing difficulties when there were clashes between appointments relating to their treatment and appointments relating to benefits, reflecting the difficulty of joining up the various aspects of care and welfare services (e.g. Lymbery, 2006). This is particularly important given that recent UK welfare reforms mean that nonattendance at agreed appointments is being increasingly linked to sanctions (Harris, 2010). In addition, both PDU and professional interviewees noted strains in the relationship with benefit staff resulting from the behaviour of some PDUs and a perception that staff tended to stigmatise drug users. This is important from the perspective of recent welfare reforms as claimants who are perceived to undermine their prospects of employment through their behaviour are also becoming increasingly subject to sanctions (Harris, 2010). As others have suggested, this is likely to make it difficult for employment support professionals to build a rapport with PDU clients (Sutton et al., 2004).

When thinking about how the new conditionality regimes might function, many PDU interviewees - and alcohol users interviewed for a subsequent study - felt that the work capability assessments were not sufficiently sensitive to their needs and, in particular, failed to take account of mental health issues and addiction. This reflects a broader tension in the categorisation of problem drug use. While public health researchers and PDUs tend to perceive problem drug use as a chronic illness (Cebulla et al., 2004; McLellan et al., 2000), policies rarely support this interpretation (Duke, 2006). These contrasting approaches to understanding drug use are important as they inform perceptions of how possible it is likely to be for PDUs to secure employment.

In considering the possibilities for PDUs moving from benefits into work, our findings support previous studies that stress the barriers PDUs face in securing employment. This includes some of the same factors creating tensions with employment service staff, such as mental and physical health problems, ongoing drug use and the need to meet treatment requirements. In addition, PDUs frequently appear to experience poor self-confidence and tend to have relatively poor educational experiences and low skills. These issues are highlighted in a review of literature relating to barriers to employment faced by drug and alcohol users (Sutton et al., 2004) which included a study comparing substance misusing women on benefits to other women who were claiming benefits but not using drugs. It found that the women not on drugs tended to have significantly higher basic skills (reading, writing and arithmetic) as well as office skills (Atkinson et al., 2001, cited in Sutton et al., 2004). The review also included a Scottish study of drug users that found many participants struggled to carry out simple tasks (Neale and Kemp, 2005, cited in Sutton et al., 2004).

One of the biggest barriers preventing the movement of PDUs into employment, however, has little to do with their own skills and qualifications 
and relates instead to the stigma associated with being a drug user. For example, other research has noted the reluctance of employers to take on ex-offenders (NACRO, 1999, cited in Sutton et al., 2004). More recent studies paint a similar picture, suggesting that potential employers are extremely wary about employing anyone with a drug dependency issue, including those on a substitute medication such as methadone (see Scott and Sillars, 2003; Spencer et al., 2008; Singleton and Lynam, 2009). Our interviewees were acutely aware of this barrier, and noted that it was further enforced where PDUs had gained a criminal record. Professionals suggested that employer attitudes needed to change and that greater public understanding of drug use, as well as potential incentive programmes for employers to take on recovering addicts, might facilitate this. Several respondents also suggested that Jobcentre Plus staff could provide more intensive support for PDUs by working more closely with drug/alcohol support agencies. Some PDUs expressed a need for intensive support from officials, including encouraging applications, following up progress and providing flexible and consistent support. Professional interviewees highlighted the importance of 'buddying' in providing the kind of support necessary to help PDUs move into employment.

All of this implies that there is a need to provide intensive and flexible support to PDUs - of the type outlined above and including approaches to engage employers - if they are to successfully move into or return to the labour market. This is supported by Dean's (2003) assessment of people with multiple problems, as well as Platt's (1995) review of research which found that the types of programme that achieved some success involved supported work, job-seeking and placement and personal competency and skill-building. Similarly, Sutton and colleagues' (2004) review of employment support programmes identified ongoing support for drug users, especially with regard to tackling relapse and the ability to refer to other support services, as crucial to success (Sutton et al., 2004).

Unfortunately, however, our findings suggest PDUs did not feel that welfare support offices were currently equipped to help them in this way. Instead, some interviewees suggested that most PDUs found employment through volunteering and that Jobcentre Plus was largely not involved in supporting those who do successfully move from benefits into employment. This suggests that further emphasis should be given in current and future policies to forging links between volunteering organisations and benefit agencies.

\section{Conclusion}

Findings from this study suggest that some aspects of recent welfare reforms, notably the simplification of benefits, may help PDUs interact with the UK's welfare system. However, the data also reinforce claims that the increased use of sanctions is unlikely to succeed in improving employment rates amongst this group, at least not without accompanying intensive support and complementary 
interventions to encourage potential employers to find jobs for individuals in this group. The situation is far too complex, and the barriers to employment too many, for sanctions alone to work in facilitating the movement of PDUs from benefits into employment. This is reflected in evidence from other countries, including the USA, where increased screening for alcohol and drug use has not reduced benefit uptake (Cheng and Lo, 2010) or the prevalence of drug misuse (see Harris, 2010). It is possible that increasing benefit sanctions in the UK, which are based on a different rationale to the USA and which are being implemented differently (see Harris, 2010), may reduce the number of PDUs claiming on welfare. However, it is important to note that this may happen without necessarily increasing levels of employment amongst PDUs (and this may, in turn, lead to increased offending see UKDPC, 2008).

The increased use of sanctions within the benefits system, including against PDUs, may be desirable for political reasons but there is currently no clear evidence that this is more successful at moving people off benefits and into work than alternative approaches. Indeed, the evidence which does exist in this area suggests there is a high potential for welfare sanctions to have a negative impact on vulnerable groups such as PDUs. Therefore the welfare reforms that are currently being implemented in the UK and elsewhere need to be carefully evaluated to explore the impact of these reforms on different subpopulations, as well as benefit claimants as a whole.

\section{Acknowledgement}

This study was funded by the Department of Work and Pensions. The views are those of the authors and not necessarily those of the DWP.

\section{Notes}

1 The term 'drug misuse' as used here refers to when a person regularly takes one or more drugs to change their mood, emotion or state of consciousness and this drug taking causes harm to the individual, their significant others or the wider community.

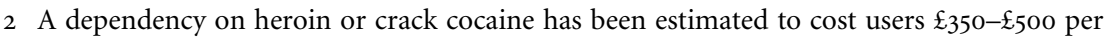
week (Cabinet Office Strategy Unit, 2003)

\section{References}

Allard, P. (2002), Life Sentences: Denying Welfare Benefits to Women Convicted of Drug Offenses, Washington, DC: The Sentencing Project.

Bargagli, A. M., Hickman, M., Davoli, M., Perucci, C. A., Schifano, P. et al. (2006), 'Drug-related mortality and its impact on adult mortality in eight European countries', European Journal of Public Health, 16: 198-202.

Barnes, H., Sissons, P., Aston, J., Dewson, S., Stevens, H., Williams, C. and Francis, R. (2010), Employment and Support Allowance: Early Implementation Experiences of Customers and Staff, DWP Research Report No. 631, London: Department for Work and Pensions.

Bauld, L., Hay, G., Mckell, J. and Carroll, C. (2010), Problem Drug Users Experiences of Employment and the Benefit System, Research Report 640, Department of Work and Pensions, http://research.dwp.gov.uk/asd/asd5/rports2009-2010/rrep640.pdf. 
Cabinet Office Strategy Unit (2003), Drugs Report: Phase 1 - Understanding the Issues, London: Cabinet Office.

Cebulla, A., Smith, N. and Sutton, L. (2004), 'Returning to normality: substance users' work histories and perceptions of work during and after recovery', British Journal of Social Work, 34: $1045-54$.

Cheng, T. C. and Lo, C. C. (2010), 'Heavy alcohol use, alcohol and drug screening and their relationship to mothers' welfare participation: a temporal-ordered causal analysis', Journal of Social Policy, 39: 4, 543-59.

Daguerre, A. (2007), Active Labour Market Policies and Welfare Reform: Europe and the US in Comparative Perspective, Basingstoke: Palgrave.

Dean, H. (2003), 'Re-conceptualising welfare-to-work for people with multiple problems and needs', Journal of Social Policy, 32: 3, 441-59.

Degenhardt, L., Hall, W., Warner-Smith, M. and Lynskey, M. (2003), 'Illicit drug use', in M. Ezzati, A. Lopez, A. Rodgers and C. J. L. Murray (eds.), Comparative Quantification of Health Risks: Global and Regional Burden of Disease Attributable to Selected Major Risk Factors, Geneva: World Health Organization, Chapter 13.

Degenhardt, L., Hallam, C. and Bewley-Taylor, D. (2009), Comparing the Drug Situation across Countries: Problems, Pitfalls and Possibilities, Briefing Paper 19, Oxford: The Beckley Foundation Drug Policy Programme, http://www.idpc.net/sites/default/files/library/ Beckley\%2oBriefing\%2019.pdf.

Department of Work and Pensions (DWP) (2008), Raising Expectations and Increasing Support: Reforming Welfare for the Future, White Paper Cm 7506, London: The Stationary Office.

Department of Work and Pensions (DWP) (2010), Universal Credit: Welfare that Works, White Paper Cm 7957, London: The Stationary Office.

Dorling, D. (2009), 'Editorial: unemployment and health', British Medical Journal, 338: b829.

Duke, K. (2006), 'Out of crime and into treatment?: the criminalization of contemporary drug policy since Tackling Drugs Together', Drugs: Education, Prevention and Policy, 13: 5, 409-15.

Dwyer, P. and Ellison, N. (2009), "We nicked stuff from all over the place": policy transfer or muddling through?', Policy and Politics, 37: 3, 389-407.

Gordon, L., Tinsley, L., Godfrey, C. and Parrott, S. (2006), 'The economic and social costs of class A drug use in England and Wales, 2003/04', in N. Singleton, R. Murray and L. Tinsley (eds.), Measuring Different Aspects of Problem Drug Use: Methodological Developments, Home Office Online Report 16/o6, http://rds.homeoffice.gov.uk/rds/pdfso6/rdsolr1606.pdf.

Gregg, P. (2008), Realising Potential: A Vision for Personalised Conditionality and Support, London: The Stationery Office.

Hales, J., Hayllar, O., Iyaniwura, C. and Wood, M. (2009), Pathways to Work: The Experiences of Existing Customers, Findings from a Survey of Existing Incapacity Benefits Customers in the First Seven Pilot Areas, DWP Research Report RR527, London: Department for Work and Pensions.

Harris, N. (2008), 'From unemployment to active jobseeking: changes and continuities in social security law in the United Kingdom', in S. Stendahl, T. Erhag and S. Devetzi (eds.), A European Work-First Welfare State, 49-78. http://130.241.16.4/bitstream/2077/ 20227/1/gupea_2077_20227_1.pdf\#page=55.

Harris, N. (2010), 'Conditional rights, benefit reform, and drug users: reducing dependency?', Journal of Law and Society, 37: 2, 233-63.

Hay, G. and Bauld, L. (2008), Population Estimates of Problematic Drug Users Who Access DWP Benefits: A Feasibility Report, DWP Working Paper No. 46, Sheffield: Department for Work and Pensions.

Hay, G., Gannon, M., MacDougall, J., Millar, T., Williams, K., Eastwood, C. and McKeganey, N. (2008), National and Regional Estimates of the Prevalence of Opiate Use and/or Crack Cocaine Use 2006/o7: A Summary of Key Findings, Home Office Research Report 9, London: Home Office. 
Henderson, S., Dohan, D. and Schmidt, L. (2006), 'Barriers to identifying substance abuse in the reformed welfare system', Social Service Review, 80: 217-38.

HM Government (2008), Drugs: Protecting Families and Communities: The 2008 Drug Strategy, London: Central Office of Information (COI).

Hoare, J. and Flatley, J. (2008), 'Drug misuse declared: findings from the 2007/08 British Crime Survey: England and Wales', Home Office Statistical Bulletin, 13/o8. London: Home Office.

Jones, A., Weston, S., Moody, A., Millar, T., Dollin, L., Anderson, T. and Donmall, M. (2007), 'The drug treatment outcomes research study: baseline report', Home Office, London.

Joyce, K. E., Smith, K. E., Sullivan, C. and Bambra, C. (2010), 'Most of industry's shutting down up here .... employability initiatives to tackle worklessness in areas of low labour market demand', Social Policy and Society, 9: 3, 337-63.

Lunt, N., O'Brien, M. and Stephens, B. (2008), 'New Welfare New Zealand: the context for social security reform', in N. Lunt, M. O'Brien and R. Stephens (eds.), New Welfare New Zealand, Melbourne: Thomson Press, pp. 3-9.

Lymbery, M. (2006), 'United we stand? Partnership working in health and social care and the role of social work in services for older people', British Journal of Social Work, 36: 7, 1119-34.

MacLeod, J. and Hickman, M. (2010), 'How ideology shapes the evidence and the policy: what do we know about cannabis use and what should we do?', Addiction, 105: 8, 1326-30.

McDonald, C. and Marston, G. (2005), 'Workfare as welfare: governing unemployment in the advanced liberal state', Critical Social Policy, 25: 3, 374-401.

McLellan, A. T., Lewis, D. C., O'Brien, C. P. and Kleber, H. D. (2000), 'Drug dependence, a chronic medical illness: implications for treatment, insurance, and outcomes evaluation', Journal of the American Medical Association, 284: 13, 1689-95.

Millar, J. (2000), Keeping Track of Welfare Reform: The New Deal Programmes, York: Joseph Rowntree Foundation.

Montoya, I. and Atkinson, J. (2002), 'A synthesis of welfare reform policy and its impact on substance users', Journal of Drug and Alcohol Abuse, 28: 133-46.

Platt, J. (1995), 'Vocational rehabilitation of drug abusers', Psychology Bulletin, 117: 416-33.

Scott, G. and Sillars, K. (2003), Employers' Attitudes to Hard-to-Employ Groups, Glasgow: Scottish Poverty Information Unit.

Singleton, N. and Lynam, B. (2009), 'Policy forum: the other half of the equation - employers' readiness to recruit problem drug users', Drugs and Alcohol Today, 9: 1, 7-11.

Singleton, N., Murray, R. and Tinsley, L. (2006), Measuring Different Aspects of Problem Drug Use: Methodological Developments (2nd edn), Home Office Online Report 16/o6, http://citeseerx.ist.psu.edu/viewdoc/download?doi=10.1.1.148.1659\&rep=rep1\&type $=$ pdf

Social Security Advisory Committee (2002), 'Fifteenth Report April 2001-March 2002', SSAC, London.

Spencer, J., Deakin, J., Seddon, T. and Ralphs, R. (2008), Getting Problem Drug Users (Back) Into Employment: Part Two, London: UKDPC.

Sutton, L., Cebulla, A., Heaver, C. and Smith, N. (2004), 'Drug and alcohol use as barriers to employment: a review of the literature', Loughborough University for Department for Work and Pensions.

UK Drug Policy Commission (UKDPC) (2008), Working Towards Recovery: Getting Problem Drug Users Into Jobs, London: UKDPC.

UNDCP (2000), 'Global illicit drug trends 200o', United Nations International Drug Control Programme, Vienna.

UNODC (2012), World Drug Report 2011, http://www.unodc.org/documents/data-and -analysis/WDR2011/WDR2011-ExSum.pdf 